\title{
Discussion on the Application Effect of Happy PE Concept in Primary School PE Teaching
}

\section{Baoqing He}

Shenzhen Yijing Primary School, Shenzhen, Guangdong, China

\begin{abstract}
The new curriculum standard points out that the ultimate goal of physical education is to guide students to establish a correct concept of lifelong physical education and promote students to extend physical exercise to practical life. In order to achieve the above goals, we must first enrich students' happy experience, so as to enhance students' inner motivation for physical education. For primary school students, they are in a critical period of life-long sports concept formation, which requires teachers must set up the happy physical education concept, make happy sports idea penetrated into each teaching link to rich students' happy experience, at the same time, also can optimize the elementary school sports teaching system and achieve the best teaching effect.
\end{abstract}

Key words: PE in primary schools; happy PE; application

The idea of happy physical education not only embodies the important position of physical education but also shows the significance of fun teaching. In essence, the concept of happy physical education is the integration of people-oriented concepts and fun teaching concepts, and the organic unity of science education concepts. From the perspective of teaching characteristics, the happy sports mode has strong vitality and flexibility and aims to meet students' happiness needs through diversified teaching methods, so as to achieve the purpose of edutainment. For primary school students, they are in the key period of good exercise habits, strengthening the effective infiltration of happy sports concept in primary school physical education has important significance for promoting students' comprehensive and benign development.

\section{The Application Value of the Happy Sports Concept}

First of all, in essence, the concept of happy physical education fundamentally breaks through the limitations of the exam-oriented education concept and is the subversion and innovation of the traditional concept of physical education. As an innovative educational concept, the concept of happy physical education not only pays more attention to the formation of habits, but also pays high attention to the students' mental health, which strengthens the health value of physical education to a great extent.

Secondly, from the point of view of teaching characteristics, a happy sports model has a strong interest and diversity, which can maximize the satisfaction of students' autonomy and personalized needs. It can be seen that the concept of happy sports has high application value, which is mainly reflected in the teaching mode and innovation and the development of students' abilities. Therefore, the majority of teachers must pay attention to it, so as to better achieve the fundamental goal of maximizing teaching efficiency.

Copyright $(2021$ by author(s) and Frontier Scientific Research Publishing Inc.

This work is licensed under the Creative Commons Attribution International License (CC BY 4.0).

http://creativecommons.org/licenses/by/4.0/ 


\section{The Concrete Application of the Happy Sports Model}

2.1 From the teaching environment, pay attention to the creation of a happy atmosphere

Happy sports mainly emphasize the significance of experiential teaching, and it is hoped that sports teaching activities can be carried out on the basis of enriching students' happy experience, so as to obtain great teaching benefits. From elementary school students' actual development characteristics, influence on their learning environment is very deep. It requires teachers to start from environmental elements, combined with the basic requirements of happy sports mode, pay attention to the happy atmosphere of the building, at the same time enhance the student feel happy and can also tap the potential of students, so as to get twice the result with half the effort. On the one hand, teachers can use humorous oral language or encouraging body language to create a harmonious physical education environment, so as to meet the psychological and emotional needs of students and make students happily into the study of physical education. On the other hand, teachers should strengthen the construction of a good teacher-student relationship and try their best to meet the interests of students, so as to provide a reliable interactive basis for the smooth implementation of happy physical education.

Taking the teaching of "running and jumping" as an example, teachers can make the teaching content into animated videos to meet the needs of students' interest cultivation, so that students can gain happy experience while acquiring theoretical knowledge, so as to realize the effective penetration of the concept of happy sports. In this process, teachers can use humorous language to strengthen students' happiness feelings, such as "do you want to be a happy little frog? Let's change!" and so on, let the students master the essentials of running and jumping in laughter, so as to enhance the learning effect of students.

2.2 Starting from the teaching models pay attention to the application of interesting methods

As mentioned above, the happy sports mode has strong interest and diversity. In order to implement the basic requirements of the happy sports concept, the majority of teachers must adopt a diversified teaching mode. First of all, in the process of theoretical teaching, PE teachers should pay attention to the introduction and application of interesting teaching methods, so as to strengthen the vitality and dynamics of theoretical teaching and enhance students' happiness feelings. It is worth noting that physical education teachers should break through the static nature of traditional physical education theory teaching, and actively create a vibrant physical education class, strive to enrich students' happy experiences and break and innovate traditional physical education mode at the same time.

Secondly, in practice teaching, the majority of teachers should not only pay attention to skill training but also need to optimize and innovate the training method, try to choose the training method that students are interested in, by no means adopt a single action demonstration training method. Take "basketball" teaching as an example, in the process of explaining the knowledge of action skills, teachers can use whiteboard teaching to guide students to master the essentials of basketball action with the help of network technology and deepen the memory of students by decomposing the action, so as to enhance the teaching effect.

In addition, because of the preservation function and animation effect of Internet technology, students can choose a reasonable way of learning according to their own actual situation, which can not only meet the personalized needs of students but also strengthen the intrinsic motivation of students. In practice teaching, teachers can integrate interesting game activities and design diversified game activities around dribble, pass, throw, and other training contents, such as "pass relay", "obstacle dribble" and so on, so as to enhance the fun value of basketball teaching and strengthen students' basketball skills. 
2.3 Start from extracurricular activities, pay attention to the formation of good habits

In addition, in order to improve the application effect of the concept of happy sports, it is necessary for the majority of teachers to expand the scope and space of sports teaching, through the development of rich extracurricular activities to achieve the above purpose to maximize the satisfaction of students' happiness needs. On the one hand, extracurricular activities are carried out in real life, which is easy to eliminate the tension of classroom teaching, to a large extent not only meet the psychological needs of students, but also meet the interests of students to create good conditions.

On the other hand, as an extension training method, extracurricular activities can play a role in strengthening the comprehensive quality of students. In extracurricular activities, students can choose the way of sports they are interested in, which can not only enhance the effect of interest cultivation but also meet the personalized needs of students. At the same time, through extracurricular activities, the value of students' autonomy is fully reflected, and they are more willing to participate in sports activities, which is very important to implement the basic purpose of the happy sports concept. For example, teachers can regularly organize students to participate in extra-curricular sports activities, either in the gym or in the open-air playground, so that students can determine the location and mode of activity, so as to improve students' participation. It is important to note that in order to ensure that the effective value of the extracurricular activities can give full play to come out, physical education teachers must strengthen the supervision and evaluation, comprehensively grasp of the students' interest in physical education learning and cultivation condition, integrate the evaluation results and adjust it as a happy sports teaching mode of reference, so as to promote the continuous improvement of the sports teaching system.

\section{The Application Effect of Happy PE Concept in Primary School PE Teaching}

The above content is summarized by the author according to his own practical experience. In the process of applying the concept of happy sports, the author has found many changes mainly reflected in the following aspects: First, the nature of students' participation has changed from passive participation to active participation, and the requirements of teaching subjects have been implemented.

Second, the advantages of core literacy cultivation are enhanced, which is not only reflected in skill training but also reflected in physical training, and it to a large extent improves and optimizes the primary school physical education teaching system.

Thirdly, teachers' awareness of self-improvement is enhanced. Under the guidance of the concept of happy sports, teachers pay more attention to the innovation of teaching mode, which is to a large extent urges teachers to make continuous progress and progress, and ultimately provides an important guarantee for strengthening the comprehensive quality of teachers. It can be seen that the application effect of the concept of happy sports is very significant, which needs to promote and permeate in practical teaching by the majority of physical education teachers.

\section{Conclusions}

The practice has proved that the concept of happy physical education is scientific and reasonable. Under its guidance, it not only breaks through the limitation and restriction of traditional physical education mode but also meets the actual needs of teachers and students' ability development. Therefore, PE teachers must master the teaching method of happy PE comprehensively, infiltrate the idea of happy PE into every link of PE teaching, innovate in the education idea and teaching method, so as to better meet the training requirements of students' lifelong PE concept, and further implement the basic requirements of effective teaching. 


\section{Conflicts of Interest}

The author declares no conflicts of interest regarding the publication of this paper.

\section{References}

[1] Zhang C.F. (2020). Analysis on the Application effect of the Concept of "Happy Sports" in Primary School Physical Education. Physical Education Teaching and Research, 4(05):123.

[2] Cheng C. (2019). On the Application Effect of the Concept of "Happy Sports" in Primary School Physical Education. World of Sports, 6(05):118-119.

[3] Tang X.H. (2019). Preliminary Study on the Application of Happy Physical Education in Primary School Physical Education. School Physical Education, 9(34):105-106.

[4] Wang Q. (2019). On the Application Effect of the Concept of "Happy Sports" in Primary School Physical Education. Xuezhoukan, 12(35):150.

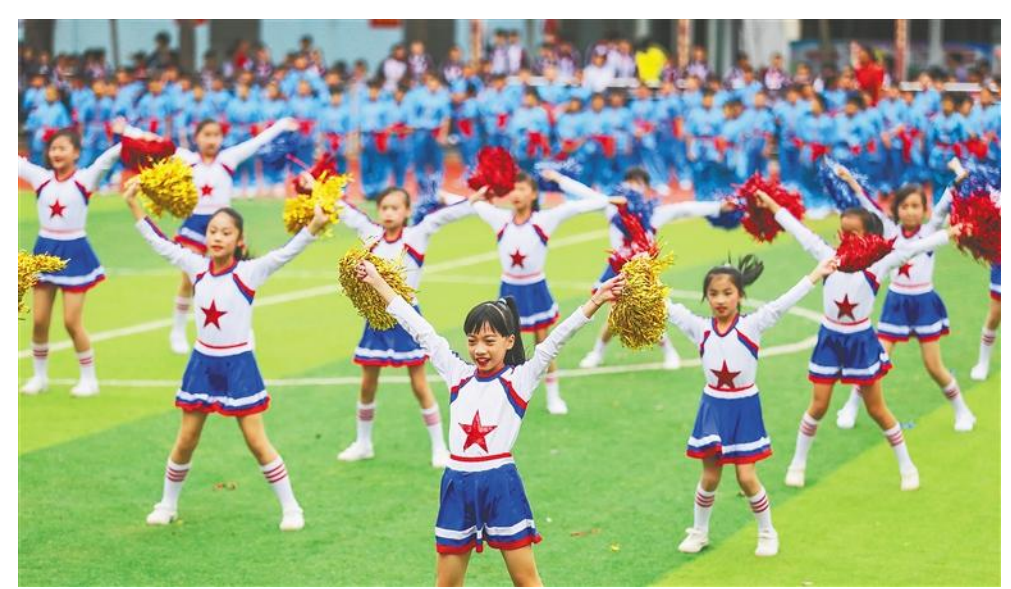

